\title{
Implementation of interprofessional education in community setting
}

\author{
Fatikhu Yatuni Asmara, ${ }^{1,}{ }^{*}$ Saekhol Bakri, ${ }^{2}$ Dian Puspita Dewi, ${ }^{2}$ Diana Nur Afifah, ${ }^{3}$ dan Tri Nur Kristina ${ }^{2}$ \\ ${ }^{1}$ Department of Nursing, Faculty of Medicine, Universitas Diponegoro, Semarang, Indonesia \\ ${ }^{2}$ Department of Medicine, Faculty of Medicine, Universitas Diponegoro, Semarang, Indonesia \\ ${ }^{3}$ Department of Nutrition, Faculty of Medicine, Universitas Diponegoro, Semarang, Indonesia
}

\section{Submitted: 10 July 2019 Revised: 4 December 2019 Accepted: 9 December 2019}

\begin{abstract}
Community health problem(s) needs to be solved collaboratively among the health care team. Interprofessional Education (IPE) is implemented to facilitate health students to collaborate before they join in the working world. The purpose of this study was to identify the experience of students, lecturers, and family members in the implementation of IPE in a community setting. All (465) sixth semester medical, nursing, and nutrition students in the Faculty of Medicine Universitas Diponegoro participated in the IPE program. Each small group contains 4-5 students who worked together in the community setting to identify family health problems, implement interventions, and evaluate the results. Focus Group Discussion (FGD) was conducted to evaluate the implementation. Twenty-four medical, nursing, and nutrition students, eight lecturers, and five family members were involved in this study. FGD was conducted separately among groups. The implementation is divided into four phases, namely, preparation, process, evaluation, and benefit. Unclear competencies and roles-responsibilities of each student in the program was the most problem faced during preparation, while obstacles during the process were difficult to set a schedule among team members. Conducting an objective assessment of both methods and tools needs to be concerned in the evaluation phase. However, students, lecturers, and family members appreciated the program and preferred to sustain the program. IPE can be implemented in a community setting to solve health problems and it can facilitate students to collaborate in a team, but it needs to be settled including preparation, process, and evaluation.
\end{abstract}

KEYWORDS community setting; implementation; interprofessional education

\section{Introduction}

Health care service is required to provide professional and quality services to patients since these patients have increased knowledge and the need for comfort when receiving the service. For that, the responsibility of providing quality health care services does not rely on a particular health profession. Instead, all health professions should be involved. Collaboration and cooperation among the health professionals both in community and clinical settings become essential. Collaboration is an inter- professional process which includes more than one profession to complete one task or to achieve an objective ${ }^{1}$. Furthermore, collaboration is an effective interprofessional process to accomplish an objective in which it cannot be achieved if each profession works alone. ${ }^{1}$ Collaboration between the physicians and nurses is essential to optimize the services given to patients. ${ }^{2}$

Interprofessional Education (IPE) is one form of collaboration which can be practiced by students

\footnotetext{
*Corresponding author: Fatikhu Yatuni Asmara

Department of Nursing, Faculty of Medicine, Universitas Diponegoro, Semarang, Indonesia, Jl. Prof. Soedarto, Tembalang, Kecamatan Tembalang, Kota Semarang, Jawa Tengah 50275, Indonesia

E-mail: fatikhu.y.asmara@gmail.com
} 
in the delivery of health care services.., ${ }^{3,5}$ IPE can be defined as a learning process in which students from various health disciplines collaborate to provide health care services to patients, and the goal is to increase the quality of care. ${ }^{6}$ IPE needs to be introduced to the students as early as possible to facilitate them to work in teams and collaborate with other students from different disciplines. Collaborating and working in teams should be introduced to the students in the academic phase before they have an internship in both clinical and community settings. ${ }^{7}$ WHO explained that collaboration in IPE would help the community to access the health care service ${ }^{8}$. Previous studies reported that communication and collaboration skills increased, and also they were satisfied with their collaborative practice by participating in the community-based interprofessional education programs. ${ }^{9-12}$

The Faculty of Medicine, Universitas Diponegoro, as one of the health education institutions in Central Java, has taken the responsibility to help the local government to increase maternal health by implementing the IPE program in the community. This program has recently been implemented in collaboration with the health district and primary health center. The IPE program is applied when two or more students from different disciplines learn from each other to improve the collaboration to provide quality services. Within this program, the students from several health professions work together to gain experience on how to deal with the health problems in the community (known as communitybased education/CBE). Previous study reported that active community participation in the CBE program increases the community's compliance with the student's interventions. ${ }^{13}$ It is expected that an appropriate combination of the IPE -CBE programs will provide an added value of $\mathrm{CBE}$.

The program involves three study programs in the Faculty of Medicine of Universitas Diponegoro, namely medicine, nursing, and nutrition. The family approach was chosen for the implementation of this program. The family recruited for the program would be supervised by a group of students, consisting of three or four students from different disciplines. The team would conduct an assessment to gain the data, identify and determine the health problem(s), plan the intervention based on the problem(s), implement the plan, and evaluate the implementation. During the process, the students were supervised by a lecturer.

This study aimed to identify the experience of students, lecturers, and community in the implementation of the IPE programs in community settings. The result will be necessary for the institution, Faculty of Medicine of Universitas Diponegoro, to improve its implementation and to increase the quality of the program.

\section{Method}

The study used a qualitative method. Focus Group Discussion was conducted to collect data. Twentyfour medical, nursing, and nutrition students, eight lecturers, and five family members were involved in this study. FGD was conducted separately among groups. It facilitated participants to share their ideas and suggestions without pressure. FGD was led by one facilitator, used guidance, and was recorded using both audio and visual aid. Furthermore, the result was analyzed qualitatively. It was identified as keywords and themes.

\section{Result}

There were four themes derived from the result, namely preparation, process, evaluation, and benefit of the program. Each theme consisted of several categories. Table 1 described the result.

\section{Discussion}

This part is going to discuss the result. The first theme is preparation. There are five categories, namely team building, integrated subject, roles and responsibilities, module or guidance book, and facilitator during preparation. Some participants stated that team building was less useful because it was held too short and too late. They suggested to conduct team building at least six months before and to introduce the IPE program to students 
Table 1. Themes, categories, and keywords

\begin{tabular}{|c|c|c|}
\hline Themes & Categories & Keywords \\
\hline \multirow[t]{11}{*}{ Preparation } & Team building & Time for team building is too short \\
\hline & & Team building starts from one or two semesters before \\
\hline & Integrated subject & Must be separated from other subjects \\
\hline & & Too many assignments plus other subjects \\
\hline & Roles and responsibilities & Unclear roles and responsibilities each profession \\
\hline & & $\begin{array}{l}\text { Roles of nursing and medical students are quite the } \\
\text { same }\end{array}$ \\
\hline & & $\begin{array}{l}\text { The competencies of IPE are not clear. Students work } \\
\text { together to solve health problems or work base on their } \\
\text { subject? }\end{array}$ \\
\hline & Module or guidance book & $\begin{array}{l}\text { Competencies must be clear whether team working and } \\
\text { collaborating or giving intervention to the family }\end{array}$ \\
\hline & & Modul is clear enough, too many assessment forms \\
\hline & & Less guidance for nutrition students \\
\hline & Facilitator & Not all facilitators understand about the program \\
\hline \multirow[t]{7}{*}{ Process } & Scheduling & Difficult to time scheduling in a group \\
\hline & & Difficult to match time with family \\
\hline & Interaction with family & Focus intervention is on nutrition problem \\
\hline & & $\begin{array}{l}\text { Students are difficult to identify the family's health } \\
\text { problems }\end{array}$ \\
\hline & Supervision & $\begin{array}{l}\text { Communication between students and facilitators can } \\
\text { be held using the phone or social media }\end{array}$ \\
\hline & & Not all facilitators come to the family \\
\hline & & Facilitators do not work together \\
\hline \multirow[t]{3}{*}{ Evaluation } & Method & Method (seminar using poster) is suitable \\
\hline & & Scoring is not transparent and late \\
\hline & Tools & The assessment form is not clear \\
\hline \multirow[t]{7}{*}{ Benefits } & Teamworking & $\begin{array}{l}\text { Students learn to work in a team with other health } \\
\text { students }\end{array}$ \\
\hline & Communication & $\begin{array}{l}\text { Helping to train communication skill with other health } \\
\text { students }\end{array}$ \\
\hline & & Helping to improve communication with the community \\
\hline & Objectives & Good and prefer to sustain \\
\hline & & Help the community to solve health problems \\
\hline & & Solve health problems comprehensively \\
\hline & Collaboration & Helping to train collaboration skill in a group \\
\hline
\end{tabular}


involved. The IPE program can be conducted in four levels, namely level 1 interprofessional education: the foundation of group skills; level 2 introduction to interprofessional education and interprofessional collaboration: exposure to the health care team; level 3 interprofessional collaboration; and level 4 becoming an effective member of the health care team ${ }^{14}$. It means that IPE needs to be implemented step by step before students work in a team to deliver health care.

The second category is an integrated subject. It is stated that IPE is an approach to the learning process, so it will be better to integrate it with other subjects. However, participants mentioned that the IPE program must be separated from other subjects because it is too many assignments to be finished. Integrated subjects in IPE implementation is a designing curriculum, which is an important preparation of the program, anditistheresponsibility of Faculty members. ${ }^{15}$ Furthermore, participants also focused on roles and responsibilities. They thought that the roles and responsibilities of each profession were unclear and there was a similarity between nursing and medical students' roles. On the one hand, students' readiness to work in interprofessional will increase as long as their roles and responsibilities are clear. ${ }^{16}$ They also confused about the focus of competencies, whether to collaborate with other health students or solve families' health problems. Understanding roles and responsibilities are part of IPE competencies according to Interprofessional Education Collaborative (IPEC) besides Values/Ethics for Interprofessional Practice, Interprofessional Communication, and Teams and Teamwork. ${ }^{17}$ Students are pursued to understand their profession's roles and responsibilities and share it with others. Students' self-assessment has a positive effect on inter-professional competencies. ${ }^{18}$

Another category is module or guidance book. The module can be used as guidance, but too many assessment forms, while nutrition students felt that their guidance is less. A composing module or guidance book is a part of designing a curriculum that is part of 10 barriers of IPE implementation. ${ }^{19}$
The module must be generic composed to used as guidance. The last category is the facilitator. The participants stated that not all facilitators understand the program, so it affected the way they supervised the students. It is stated that one of the barriers to implementing the IPE program in a developing country is resource limitation, namely lecturers or facilitators. The same perception of IPE among facilitators is important. It will support successful program implementation. ${ }^{20}$

The second theme processes. During the process, the participants struggled with time scheduling both in a group and in a family. They stated that it was difficult to match the time among group members and to match the time with the family. Arranging schedule is part of communication and teamwork, which are competencies of IPE, according to IPEC. ${ }^{17}$ A good schedule in a group shows that students can communicate and work in a team.

Furthermore, the participants complained about the supervision process. Even though communication between students and facilitators can be held by using the telephone or social media, the participants stated that not all facilitators came to the field together with the students. Facilitators did not give an example of collaboration because they supervised individually. The supervision process is a teaching process. It is part of 10 barriers that need to be concerned in implementing the IPE program. Most developing countries face this problem. ${ }^{19}$ It must be well planned in curriculum design, which is the responsibility of Faculty members. ${ }^{15}$

The third theme is evaluation. The participants stated that the assessment method, namely the seminar using the poster as a media, was suitable. However, it needs revising in the form and the scoring must be clearer. Seminar was conducted three times. The first seminar was to identify need assessment, define health problems, compose planning of intervention. The second assessment was to present the implementation of intervention and result, while the last seminar was to share evaluation and planning for further intervention. 
Students will get feedback in every seminar to improve their performance in the next seminar. The assessment implemented is part of the formative assessment. It is suitable for the IPE program because formative assessment will help students to improve their performance..$^{20}$

Furthermore, knowledge, transferable skills, professionalism, and attitudes are important elements for assessment which is assessed during seminar ${ }^{21}$. Composing a clear form and score are suggestions to improve the program. It is part of defining assessment instruments in assessment processes besides formulating questions, setting the assessment processes, defining assessment instruments, analyzing the result, and disseminating the choices. ${ }^{22}$

The last theme is the benefit of the program. It was stated that the program will increase communication skills both in a group and with a family. It is stated that IPE facilitates the students to improve interprofessional communication skills. ${ }^{23}$ After the implementation of IPE, students gained a strong confidence in communication with other professions. ${ }^{24}$ Furthermore, the participants stated that collaboration skill will increase by implementing the program. IPE is very effective and helpful to improve teamwork because IPE provides a chance for students to work together to deliver health care. ${ }^{25}$ The same idea stated that IPE can facilitate students to gain unique experiences related to collaboration, coordination, patient management, holistic intervention, and services. ${ }^{26}$ IPE also helps the health profession to improve skills, knowledge, and attitudes into collaboration. ${ }^{27}$ An increased knowledge of importance with teamwork and collaboration, learning professional roles, and respecting other professional points of view are focusing on IPE implementation. ${ }^{24}$ IPE increased the quality of care by improving the behavior of the health care team in conducting collaboration..$^{28}$ The participants stated that the objectives of the program were good; they appreciated the program and prefer to sustain the program. It helps students to solve families' health problems and to solve health problems comprehensively. Furthermore,
IPE is also the potential to impact patient care by working together. ${ }^{29}$ Students' awareness of social health problems improves as well as by finishing assignment tasks in IPE program ${ }^{30}$. Subsequently, community capacity is affected by the students acting as a catalyst by implementing IPE in community-based service-learning programs. ${ }^{31}$

The study is discussed about the experience of students and facilitators in implementing IPE in the community setting. It will help other institutions to get the lesson learned about its implementation, including preparation, process, evaluation, and benefit. Furthermore, it is suggested to conduct further research in the quantitative method to get more data about implementation.

\section{Conclusion}

IPE program is preferable to be implemented in a community setting. It facilitates students to learn in teamwork and solve families' health problems collaboratively. However, it needs improvement both in preparation, process, and evaluation.

\section{Acknowledgment}

The Research and Community Services Unit of Faculty of Medicine Universitas Diponegoro as my sponsor.

\section{Conflict of interests}

The study will give experience for institutions that are going to implement IPE in the community setting.

\section{References}

1. Bronstein, Laura R. A model for interdisciplinary collaboration. Social Work. 2003;48(3):297306.

2. Liaw SY, Zhou WT, Lau TC, Siau C, Chan SW. An interprofessional communication training using simulation to enhance safe care for a deteriorating patient. Nurse Education Today. 2014 1;34(2):259-64.

3. McPherson K, Headrick L, Moss F. Working and learning together: good quality care depends 
on it, but how can we achieve it?. BMJ Quality \& Safety. 2001;10(suppl 2):ii46-53.

4. Horder J. Interprofessional collaboration and interprofessional education. The British Journal of General Practice. 2004;54(501):243.

5. Perkin K. Nurse practitioners and interprofessional collaboration. Journal of interprofessional care. 2011;25(4):243.

6. Buring SM, Bhushan A, Broeseker A, Conway S, Duncan-Hewitt W, Hansen L, Westberg S. Interprofessional education: definitions, student competencies, and guidelines for implementation. American Journal of Pharmaceutical Education. 2009; 73 (4).

7. Curran VR, Sharpe D, Forristall J. Attitudes of health sciences faculty members towards interprofessional teamwork and education. Medical education. 2007;41(9):892-6.

8. World Health Organization. Framework for Action on Interprofessional Education \& Collaborative Practice. Geneva; Health Professions Network Nursing and Midwifery Office within the Department of Human Resources for Health; 2010. Available on: http://www.who.int/hrh/nursing_midwifery/ en/

9. Salam A. Community and Family Case Study: a community-based educational strategy to promote Five Star Doctors for the 21st century. SouthEast Asian Journal of Medical Education. 2009;3(1):20-4.

10. Giordano C, Arenson C, Lyons KJ, Collins L, Umland E, Smith K, et al. Effect of the health mentors program on student attitudes toward team care. Journal of allied health. 2013;42(2):120-4.

11. De Los Santos M, McFarlin CD, Martin L. Interprofessional education and service-learning: a model for the future of health professions education. Journal of Inter-professional Care. 2014; 28(4): 374-375.

12. Asakawa T, Kawabata H, Kisa K, Terashita T, Murakami M, Otaki J. Establishing communitybased integrated care for elderly patients through interprofessional teamwork: A qualitative analysis. Journal of Multidisciplinary Healthcare. 2017; 10: 399-407.

13. Kristina TN, Majoor GD, Van Der Vleuten CP. Comparison of outcomes of a communitybased education program executed with and without active community involvement. Medical education. 2006;40(8):798-806.

14. Salfi J, Solomon P, Allen D, Mohaupt J, Patterson C. Overcoming all obstacles: a framework for embedding interprofessional education into a large, multisite Bachelor of Science Nursing program. Journal of Nursing Education. 2012 Feb 1;51(2):106-10.

15. Kahaleh AA, Danielson J, Franson KL, Nuffer WA, Umland EM. An interprofessional education panel on development, implementation, and assessment strategies. American Journal of Pharmaceutical Education. 2015 Aug 25;79(6):78.

16. Soubra L, Badr SBY, Zahran EM, Aboul-Seoud M. Effect of Interprofessional Education on Role Clarification and Patient Care Planning by Health Professions Students. Health Professions Education. Health Professions Education. 2017; 4(4): 317-328.

17. Soubra L, Badr SB, Zahran EM, Aboul-Seoud M. Effect of Interprofessional Education on Role Clarification and Patient Care Planning by Health Professions Students. Health Professions Education. 2018;4(4):317-28.

18. Sevin AM, Hale KM, Brown NV, McAuley JW. Assessing interprofessional education collaborative competencies in service-learning course. American journal of pharmaceutical education. 2016;80(2):32.

19. Sunguya BF, Hinthong W, Jimba M, Yasuoka J. Interprofessional education for whom?challenges and lessons learned from its implementation in developed countries and their application to developing countries: a systematic review. PloS one. 2014;9(5):e96724.

20. Anderson ES, Kinnair D. Integrating the assessment of interprofessional education into the health care curriculum. Journal of Taibah University Medical Sciences. 2016;11(6):552-8. 
21. Mpofu R, Imalingat A. The development of an instrument for assessing communitybased education of undergraduate students of community and health sciences at the University of the Western Cape. Education for Health. 2006;19(2):166-78.

22. Reeves S, Barr H. Twelve steps to evaluating interprofessional education. Journal of Taibah University Medical Sciences. 2016;11(6):601-5.

23. Kirwin J, Greenwood KC, Rico J, Nalliah R, DiVall M. Interprofessional curbside consults to develop team communication and improve student achievement of learning outcomes. American journal of pharmaceutical education. 2017;81(1):15.

24. Carr S. Examining health professional students' attitudes on interprofessional education. Open Access Dissertations. Paper 309. University of Rhode Island; 2015. Available from: http:// digitalcommons.uri.edu/oa_diss/309

25. Wagner J, Liston B, Miller J. Developing interprofessional communication skills. Teaching and learning in nursing. 2011;6(3):97101.

26. Opina-Tan LA. A pilot implementation of interprofessional education in a community- academe partnership in the Philippines. Education for Health. 2013;26(3):164.

27. Claramita, M. Communication and Interprofessional Teamwork. Buku Panduan Umum CFHC-IPE. Yogyakarta: Fakultas Kedokteran Universitas Gajah Mada;2014.

28. Riskiyana R, Claramita M, Rahayu GR. Objectively measured interprofessional education outcome and factors that enhance program effectiveness: a systematic review. Nurse education today. 2018;66:73-8.

29. Posey S, Brady J, Pate K, Smith J, Peveto S. Description and assessment of a pilot interprofessional education case competition activity. Currents in Pharmacy Teaching and Learning. 2018;10(4):505-10.

30. Gallagher P, Pullon S, Skinner $M$, McHugh P, McKinlay E, Gray L. An interprofessional community education project as a socially accountable assessment. Journal of Interprofessional care. 2015;29(5):509-11.

31. Martens, H., \& Lairamore, C. The role of student adaptability in interprofessional education. Journal of Interprofessional Education \& Practice. 2016;5:45-51 